HEART

Economic Evaluation of ASCOT-BPLA: Antihypertensive treatment with an amlodipine-based regimen is cost-effective compared to an atenolol-based regimen

Peter Lindgren, Martin Buxton, Thomas Kahan, et al.

Heart published online October 4, 2007

doi: 10.1136/hrt.2007.127217

Updated information and services can be found at:

http://heart.bmj.com/content/early/2007/10/04/hrt.2007.127217

These include:

$\mathbf{P}<\mathbf{P} \quad$ Published online October 4, 2007 in advance of the print journal.

Email alerting service

Receive free email alerts when new articles cite this article. Sign up in the box at the top right corner of the online article.

Notes

Advance online articles have been peer reviewed and accepted for publication but have not yet appeared in the paper journal (edited, typeset versions may be posted when available prior to final publication). Advance online articles are citable and establish publication priority; they are indexed by PubMed from initial publication. Citations to Advance online articles must include the digital object identifier (DOIs) and date of initial publication.

To order reprints of this article go to:

http://heart.bmj.com/cgi/reprintform

To subscribe to Heart go to:

http://heart.bmj.com/subscriptions 


\title{
Economic Evaluation of ASCOT-BPLA: Antihypertensive treatment with an amlodipine-based regimen is cost-effective compared to an atenolol-based regimen
}

Peter Lindgren ${ }^{1,2}$, Martin Buxton ${ }^{3}$, Thomas Kahan ${ }^{4}$, Neil R Poulter ${ }^{5}$, Björn Dahlöf ${ }^{6}$, Peter S Sever ${ }^{5}$, Hans Wedel ${ }^{7}$, Bengt Jönsson ${ }^{8}$ on behalf of the ASCOT trial investigators

${ }^{1}$ i3innovus, Stockholm, Sweden

${ }^{2}$ Institute of Environmental Medicine, Karolinska Institutet, Stockholm, Sweden

${ }^{3}$ Brunel University, Uxbridge, UK

${ }^{4}$ Department of Clinical Science, Danderyd Hospital, Karolinska Institutet, Stockholm, Sweden

${ }^{5}$ Imperial College, London, UK

${ }^{6}$ Sahlgrenska University Hospital/Östra, Göteborg, Sweden

${ }^{7}$ Nordic School of Public Health, Göteborg, Sweden

${ }^{8}$ Centre for Health Economics, Stockholm School of Economics, Stockholm, Sweden

\section{Keywords}

Hypertension, primary prevention, amlodipine, atenolol, cost-effectiveness

\author{
Address for correspondence: \\ Peter Lindgren \\ i3innovus \\ Vasagatan 38 \\ 11120 Stockholm \\ Sweden \\ Fax: +46854528549 \\ peter.lindgren@healtheconomics.se
}

The Corresponding Author has the right to grant on behalf of all authors and does grant on behalf of all authors, an exclusive licence (or non exclusive for government employees) on a worldwide basis to the BMJ Publishing Group Ltd and its Licensees to permit this article (if accepted) to be published in HEART editions and any other BMJPGL products to exploit all subsidiary rights 


\section{Abstract \\ Objective}

To assess the cost-effectiveness of an amlodipine-based strategy compared to an atenololbased strategy in the treatment of hypertension in the UK and Sweden.

Design

A prospective, randomized trial complemented with a Markov model to assess long-term costs and health effects.

\section{Setting}

Primary care.

\section{Patients}

Patients with moderate hypertension and three or more additional risk factors.

\section{Interventions}

Amlodipine 5-10 mg with perindopril 4-8 mg added as needed or atenolol 50-100 mg adding bendroflumethiazide $1.25-2.5 \mathrm{mg}$ and potassium as needed

\section{Main outcome measures}

Cost per cardiovascular event and procedure avoided, and cost per quality-adjusted life year gained.

\section{Results}

In the UK, the cost to avoid one cardiovascular event or procedure would be $18965 €$, and the cost to gain one quality-adjusted life year would be $21875 €$. The corresponding figures for Sweden were $13210 €$ and $16856 €$.

\section{Conclusions}

Compared to the thresholds applied by NICE and in the Swedish National Board of Health and Welfare's Guidelines for Cardiac Care, an amlodipine-based regimen is costeffective for the treatment of hypertension, compared to an atenolol-based regimen in the population studied. 


\section{Introduction}

Optimal first line therapy and subsequent sequencing of antihypertensive drugs has been controversial for decades. This is reflected in different recommendations made in recent guidelines worldwide. [1-4] Before 1995, almost all randomized trial evidence on hypertension management related to diuretics and to a lesser extent beta-blockers. [5] However newer drug classes were increasingly being used and have consequently been evaluated in major trials. Enthusiasm for any potential advantages of the newer agents (at least on surrogate end points) has been tempered in some situations by concerns over their increased cost. Despite the reality that the majority of hypertensive patients need at least two agents to reach currently-recommended targets, until recently no trial data were available to compare the benefits of newer combinations of drugs with the standard most commonly used regimen of a beta-blocker with a diuretic.

The Blood-Pressure-Lowering Arm of the Anglo-Scandinavian Cardiac Outcomes Trial (ASCOT-BPLA) randomized 19257 patients to receive either amlodipine 5-10 mg adding perindopril $4-8 \mathrm{mg}$ as needed to reach BP targets, or atenolol $50-100 \mathrm{mg}$ adding bendroflumethiazide $1.25-2.5 \mathrm{mg}$ and potassium as needed.

Patients included in the trial were men and women aged between 40 and 79 years, with either untreated hypertension (a systolic blood pressure $\geq 160 \mathrm{~mm} \mathrm{Hg}$ or a diastolic blood pressure $\geq 100 \mathrm{~mm} \mathrm{Hg}$ ) or treated hypertension with a systolic blood pressure $\geq 140 \mathrm{~mm}$ $\mathrm{Hg}$ or a diastolic blood pressure $\geq 90 \mathrm{~mm} \mathrm{Hg}$. Patients were also required to have at least three of the following risk-factors: male sex, age above 55 years, smoking, left ventricular hypertrophy, other abnormalities on electrocardiogram, type 2 diabetes, peripheral arterial disease, previous stroke or transient ischemic attack, microalbuminuria or proteinuria, a ratio of plasma total cholesterol to HDL-cholesterol of 6 or higher, or a family history of early CHD. The trial was stopped prematurely after a median of 5.5 years due to a significant beneficial effect of the amlodipine-based regimen on all-cause mortality (HR 0.89, 95\% CI:0.81-0.99). The hazard ratio (HR) for the primary endpoint (myocardial infarction (MI) including silent events and fatal CHD) was 0.90 (95\% confidence interval, CI: $0.79-1.02$ ) in favour of the amlodipine-based regimen. There were also significant reductions in the number of fatal and non-fatal strokes (HR 0.77, 95 $\%$ CI: $0.66-0.89$ ), total cardiovascular events and procedures (HR 0.84, 95\% CI: $0.78-$ 0.90 ) and in the incidence of new-onset diabetes in the amlodipine-based group (HR 0.70, 95\% CI: $0.63-0.78)$. [6]

Looking only at the cost of medication, newer treatments (such as amlodipine and perindopril) are typically more expensive than their older comparators (such as atenolol and thiazides) but in ASCOT they induced superior preventive effects on all major CV outcomes. In order to make a rational decision when allocating resources in health care, it is necessary to take potential savings due to decreased morbidity and mortality into consideration. If the net costs still indicate that the newer strategy adds costs, a formal estimation of the cost-effectiveness of the treatment is necessary. The scope of this study was to conduct an economic evaluation of ASCOT-BPLA. This prospective economic evaluation was a prespecified analysis of the trial. Analyses were conducted for the UK and Sweden, the two largest contributors in terms of numbers of patients in the trial. 


\section{Material and methods}

Two approaches were taken in the analysis of the cost-effectiveness of the amlodipinebased regimen: A within-trial analysis estimating the costs and events avoided during the trial period; and a modelling approach extrapolating costs and the potential benefits of avoiding events on long-term survival and quality-adjusted survival over the life-time of the patients.

In the within-trial analysis, resources used during the trial period (and being recorded on the case report forms) were multiplied by their unit cost, and an average cost per patient was estimated. Resources used included use of study drug, end-point related hospitalizations, non-endpoint related hospitalizations and concomitant medications using standard published sources for unit costs. [7-11] Prices are expressed in Euros (€), using the average exchange rates during 2006 to convert for British Pounds and Swedish Kronor to the $€(1 €=0,68$ GBP, 9,25 SEK). [12] For a more in-depth description of the costing approach, please refer to our previously reported study of the lipid-lowering arm of ASCOT. [13] In the within-trial analysis, we used the average total number of events per patient during the trial as the measure of effectiveness.

To estimate long-term cost and effects, a Markov model [14] consisting of six states was constructed: Event free, diabetes, MI, coronary revascularization, stroke, and death. The four event states (MI, diabetes, stroke and revascularization) are implemented as tunnel states to allow for differentiation of costs and lost utility over time. Patients in the event free state stand a risk of suffering any of the four events, which in the case of strokes and MI:s may or may not be fatal. Patients in the event states either die or remain within their current state for the rest of the simulation. This means that only first events are explicitly incorporated in the model. Patients developing diabetes (or having diabetes at baseline), have a subsequent risk of developing MI, stroke or undergoing revascularization.

The transition probabilities used in the model are derived from the clinical trial through survival modelling, with the exception of the risk of an event being fatal which was estimated through logistic regression. These data are available online. Mortality following an event was estimated based on the entire trial sample (i.e. not estimated separately by treatment arm). This means that we are assuming no difference in mortality after an event for the two treatments. Any potential survival benefit is thus only caused by a difference in the risk of events. To avoid an underestimation of the mortality in higher age groups which were not represented in the trial, the model is programmed so that mortality does not fall below that of the general population (stratified by age and gender). [15]

The cost of the study drug is based on the mean number of days each dose was prescribed during the trial period and the daily cost of the drug (see table 1). Because perindopril is not available on the Swedish market it was assumed to have the same relative price compared to the other study drugs as in the UK $(0.81 €$ per $4 \mathrm{mg})$. We also conducted analyses where it was assumed to have the same price as the two most commonly used ACE-inhibitors in Sweden (ramipril $10 \mathrm{mg}$ and enalapril $20 \mathrm{mg}, 0.18 €$ and $0.05 €$ respectively). 
Table 1. Drug costs (€) used in the analysis

\begin{tabular}{|l|l|l|}
\hline & UK & Sweden \\
\hline Amlodipine 5 mg & 0,69 & 0,54 \\
Amlodipine 10 mg & 1,03 & 0,83 \\
Perindopril 4 mg & 0,54 & 0,81 \\
Perindopril 8 mg & 1,09 & 0,81 \\
Doxazosin GITS 4 mg & 0,49 & 0,54 \\
Doxazosin GITS 8 mg & 0,49 & 1,07 \\
Atenolol 50 mg & 0,05 & 0,04 \\
Atenolol 100 mg & 0,04 & 0,07 \\
BFZ/K+ 1.25 mg & 0,05 & 0,13 \\
BFZ/K+ 2.50 mg & 0,11 & 0,26 \\
\hline
\end{tabular}

Source: Swedish Drug Tariff (FASS) and Monthly Index of Medical Specialities [10, 11]

Costs for events were estimated by comparing the resource consumption during the year prior to the event to that one and two years following it (data available online). Health economic guidelines in Sweden and the UK differ in their view of costs caused by lost production (indirect costs) $[16,17]$ which Swedish guidelines recommend including, whereas the UK guidelines do not. Therefore only Swedish analyses incorporate indirect costs. This was based on a study of indirect costs and quality-of-life in Swedish ASCOTpatients. [18] Two measures of health outcomes were included in the model: life-years gained (LYG) based on the predicted survival in the two treatment groups and qualityadjusted life years (QALY) gained. In the latter case each life-year is weighted according to the health status of the patients. The weights used (called utility weights) are normally between 1 and 0 where 1 represents a health state equal to perfect health and 0 to a health state equivalent to death. Event-free patients are assumed to have the same utility weights as individuals in the general population (adjusted for age and gender). [19, 20] To account for the effect of events, data from the above mentioned survey of Swedish patients was used. [18] This study indicated that patients with MI had moved back to their original utility level after one year, while no such improvement was seen in stroke patients. No data were collected for patients undergoing coronary revascularization. We therefore assume that they had a slightly smaller decrease in utility than the average patients with MI, based on results from another Swedish survey. [21]

Uncertainty was incorporated into the model through probabilistic analysis using $2^{\text {nd }}$ order Monte Carlo simulation. 1000 simulations where performed. In each of the simulations, each parameter was sampled from its underlying distribution. The distributions were estimated by performing non-parametric bootstrapping of each parameter. [22] Uncertainty was reported in the form of cost-effectiveness acceptability curves. [23]

In the base-case, a cohort similar to that of the clinical trial was analysed (63 years of age, $19 \%$ female, $27 \%$ diabetic). Patients were assumed to be treated for 6 years, and followed for the remainder of their life. In the long-term model, costs and effects were discounted at $3.5 \%$ per annum in the UK and $3 \%$ per annum in Sweden in accordance with guidelines in the two countries. 


\section{Results}

Table 2 shows the results from the within-trial analysis. As expected in the amlodipinebased group, the cost of the study drugs was higher compared to the atenolol-based strategy, but there were lower costs for all other resource categories, thus offsetting 38 $50 \%$ of the drug costs during the 5.5-year trial period.

Table 2. Mean costs, number of events and incremental cost-effectiveness during the trial period.

\begin{tabular}{|c|c|c|c|c|}
\hline & \multicolumn{2}{|c|}{ UK } & \multicolumn{2}{|c|}{ Sweden } \\
\hline & $\begin{array}{c}\text { Amlodipine- } \\
\text { based }\end{array}$ & Atenolol-based & $\begin{array}{c}\text { Amlodipine- } \\
\text { based }\end{array}$ & Atenolol-based \\
\hline $\begin{array}{l}\text { Mean cost }(€) \text { per } \\
\text { patient }\end{array}$ & & & & \\
\hline Study drug & $2440(2418 ; 2462)$ & $599(590 ; 608)$ & $2850(2820 ; 2881)$ & $1274(1254 ; 1294)$ \\
\hline Outpatient visits & $2440(2425 ; 2455)$ & $2525(2509 ; 2543)$ & $2240(2227 ; 2254)$ & $2318(2303 ; 2334)$ \\
\hline $\begin{array}{l}\text { Concomitant } \\
\text { medications }\end{array}$ & $2167(2127 ; 2207)$ & $2418(2375 ; 2459)$ & $2396(2353 ; 2438)$ & $2649(2604 ; 2693)$ \\
\hline $\begin{array}{l}\text { DRG } \\
\text { hospitalizations }\end{array}$ & $766(718 ; 816)$ & $1036(976 ; 1097)$ & $1068(1000 ; 1136)$ & $1448(1364 ; 1531)$ \\
\hline $\begin{array}{l}\text { Other } \\
\text { hospitalizations }\end{array}$ & $3352(3148 ; 3557)$ & $3447(3221 ; 3673)$ & $2523(2369 ; 2678)$ & $2595(2425 ; 2765)$ \\
\hline Total cost & $\begin{array}{l}11166 \\
(10942 ; 11391)\end{array}$ & $\begin{array}{l}10026 \\
(9775 ; 10277)\end{array}$ & $\begin{array}{l}11078 \\
(10889 ; 11267)\end{array}$ & $\begin{array}{l}10283 \\
(10071 ; 10496)\end{array}$ \\
\hline $\begin{array}{l}\text { Events per } \\
\text { patient }\end{array}$ & & & & \\
\hline Primary endpoint ${ }^{1}$ & $\begin{array}{l}0.047 \\
(0.043 ; 0.052)\end{array}$ & $\begin{array}{l}0.054 \\
(0.049 ; 0.059)\end{array}$ & $\begin{array}{l}0.047 \\
(0.043 ; 0.052)\end{array}$ & $\begin{array}{l}0.054 \\
(0.049 ; 0.059)\end{array}$ \\
\hline $\begin{array}{l}\text { All events and } \\
\text { procedures } \\
\text { Cost- } \\
\text { effectiveness* }\end{array}$ & $\begin{array}{l}0.216 \\
(0.203 ; 0.229)\end{array}$ & $\begin{array}{l}0.276 \\
(0.261 ; 0.291)\end{array}$ & $\begin{array}{l}0.216 \\
(0.203 ; 0.229)\end{array}$ & $\begin{array}{l}0.276 \\
(0.261 ; 0.291)\end{array}$ \\
\hline $\begin{array}{l}\text { Cost to avoid one } \\
\text { primary event } \\
\text { Cost to avoid one } \\
\text { event or procedure }\end{array}$ & $\begin{array}{l}161364 \\
(74752 ; 4327288) \\
18965 \\
(11591 ; 31855)\end{array}$ & & $\begin{array}{l}112402 \\
(49597 ; 3106460) \\
13210 \\
(7262 ; 23392)\end{array}$ & \\
\hline
\end{tabular}

${ }^{1}$ Silent and non-silent MI and fatal CHD.

Mean values and 95\% confidence intervals. DRG = Diagnosis Related Group (potentially end-point related hospitalizations)

* Compared with atenolol-based therapy

Table 3 shows modelled lifelong predictions of costs, outcomes, and cost-effectiveness. The chief explanatory factor for the difference in survival and quality adjusted survival is the difference in discounting recommended in the UK and Swedish guidelines (3.5 and $3 \%$ per year). This also affects the total predicted costs. The inclusion of indirect costs in the Swedish analysis is of minor importance due to the mean age of the population (63 years) when included in the trial. 
Table 3. Predicted per patient life-time costs $(€)$, health outcomes and incremental costeffectiveness.

\begin{tabular}{|c|c|c|c|c|}
\hline & \multicolumn{2}{|c|}{$\mathbf{U K}^{\mathbf{1}}$} & \multicolumn{2}{|c|}{ Sweden $^{2}$} \\
\hline & $\begin{array}{l}\text { Amlodipine- } \\
\text { based }\end{array}$ & Atenolol-based & $\begin{array}{l}\text { Amlodipine- } \\
\text { based }\end{array}$ & Atenolol-based \\
\hline Costs & & & & \\
\hline Drug cost & 3107 & 1069 & 4470 & 2480 \\
\hline Event cost & 2268 & 2471 & 3117 & 3361 \\
\hline Indirect costs & na & na & 215 & 278 \\
\hline Total cost & 5376 & 3540 & 7802 & 6119 \\
\hline Health outcomes & & & & \\
\hline Life-expectancy & 11.69 & 11.59 & 12.49 & 12.37 \\
\hline $\begin{array}{l}\text { Quality adjusted life- } \\
\text { expectancy }\end{array}$ & 8.84 & 8.76 & 9.82 & 9.72 \\
\hline $\begin{array}{l}\text { Incremental cost- } \\
\text { effectiveness }^{3}\end{array}$ & & & & \\
\hline Cost per LYG & 17857 & & 14022 & \\
\hline Cost per QALY gained & 21875 & & 16856 & \\
\hline
\end{tabular}

${ }^{1}$ Costs and effects discounted at $3.5 \%$ per annum

${ }^{2}$ Costs and effects discounted at $3 \%$ per annum

${ }^{3}$ Relative to atenolol-based regimen

LYG = Life Years Gained; QALY = Quality Adjusted Life years

The cost-effectiveness acceptability curve shown in figure 1 shows the probability, given our data that the amlodipine-based strategy is cost-effective for different levels of willingness-to-pay to gain one QALY. The difference between the UK and Sweden is once again mainly due to the difference in discount rates, where the higher rate used in the UK leads to a lower valuation of future cost offsets and health gains compared to Sweden, and thus a lower probability of the strategy being considered cost-effective.

$<$ Figure $1-$ CEAC $>$

The assumptions in the model were tested in one-way sensitivity analyses. These indicated that the most sensitive variable is the proportion of females in the population, followed by the discounting factor used (data available online). In an all-female population, the incremental cost-effectiveness ratio (ICER) was $32000 €$ per QALY in the UK and $24178 €$ per QALY in Sweden. Factors such as the average age, changes in the costs caused by events and the utility reduction caused had very limited impact on the results, as had extrapolating the duration of the intervention beyond the trial period. Using the price of enalapril or ramipril as proxies for the price of perindopril in Sweden lead to lower cost-effectiveness ratios (5 $964 €$ and $3606 €$ per QALY gained), due to the low prices of these drugs (generic enalapril is the cheapest antihypertensive drug on the Swedish market). The introduction of generic amlodipine also have a large impact of the results. At a price of $0.10 €$ per day in Sweden and $0.15 €$ per day in the UK the cost to gain one QALY becomes $7257 €$ and $8372 €$ in the respective countries. 


\section{Discussion}

In the UK, our study indicates a cost of $18695 €$ to prevent one cardiovascular event or procedure, or $21875 €$ to gain one QALY during with six years of treatment with the amlodipine-based, compared with the atenolol-based regimen. This falls well below the threshold value of $20000 \mathrm{GBP}$ (29000 €) per QALY included in the most recent NICE guidelines to indicate cost-effectiveness. [17] The corresponding figures were 13210 and $16856 €$ in Sweden, where the National Board of Health and Welfare has published guidance for prioritizations in cardiovascular medicine. [24] In this guidance an ICER below 100000 SEK/QALY (11 000 €) was classified as low, and a ratio below 500000 SEK/QALY (55000 €) as moderate. Using these criteria, the cost-effectiveness ratio in our Swedish analyses fall just above the 'low' threshold.

There is reason to believe that the cost-effectiveness ratios reported here are somewhat overestimated. Although the model incorporates new-onset diabetes as an end-point, the costs associated with the microvascular complications due to diabetes are not included since they are likely to occur after the end of the trial. Diabetes is also associated with excess non-cardiovascular mortality, which is not incorporated here. Indeed, excluding the additional cost for diabetes has a very limited impact on the results of our model, leading to an increase in the ICER of about $100 €$. Using the cost reported in patients with no or microvascular complications only (assuming macrovascular complications are captured in the events costs of our model) that was reported in the CODE-2 in Sweden (1762 €) gives an ICER of $16450 €$. This may still be an underestimation, as the largest cost increase in CODE-2 was observed for patients with both micro- and macrovascular complications. [25] Costs included were based on the data collected in the trial which has the advantage of giving very high internal validity. Some potentially important costs were not collected, and are thus omitted from the event costs. This includes costs for rehabilitation following a stroke and costs for admittance to nursing home facilities. Furthermore, with the expiration of the patent on amlodipine, drug prices have fallen. This will of course lead to even more beneficial cost-effectiveness ratios. For example, in our model, a reduction in the price of amlodipine by $30 \%$ would give a cost-effectiveness ratio of $17000 € / Q A L Y$ in the UK and $13500 € / Q A L Y$ in Sweden. Indeed, with the current price of $0.10 €$ per day for amlodipine in Sweden and $0.15 €$ in the UK the cost effectiveness ratio would be $7257 € /$ QALY in Sweden and $8372 € 7$ QALY in the UK.

Some authors have argued for the inclusion of costs associated with increased survival (consumption minus production) to properly analyze the cost-effectiveness from a societal perspective. [26, 27] Such data are available for Sweden. [28] Including them in the analysis increases the cost-effectiveness ratio somewhat: $15900 €$ per QALY gained.

\section{Conclusion}

Based on the threshold values for cost-effectiveness employed by the authorities in Sweden and the UK, an amlodipine-based treatment regimen appears to be cost-effective compared to an atenolol-based regimen in patients with moderate hypertension and additional risk factors. 


\section{Acknowledgements}

The study was supported by the principal funding source, Pfizer, New York, USA. A full list of the ASCOT investigators may be found elsewhwere. [29]

\section{Conflict of interest statement}

PL, MB, TK, NP, BD, PS, HW and BJ have served as consultants to and received travel expenses, payment for speaking at meetings or funding for research from pharmaceutical companies marketing anti-hypertensive drugs, including AstraZeneca, Sanofi-Aventis, Bayer, Bristol-Myers Squibb Co, Merck, Sharpe and Dohme, Novartis, Pfizer, , Schering, and Servier. PL, MB, TK, NP, BD, PS, HW and BJ received financial support from Pfizer to cover administrative and staffing costs of ASCOT, and travel, accommodation expenses or both incurred by attending relevant meetings.

\section{Figure legends}

Figure 1. Cost-effectiveness acceptability curve indicating the probability that the amlodipine-based strategy is cost-effective compared to the atenolol-based strategy at different willingness-to-pay thresholds to gain one quality adjusted life-year. 


\section{References}

1. 2003 European Society of Hypertension-European Society of Cardiology guidelines for the management of arterial hypertension. J Hypertens, 2003. 21: 1011-53.

2. Chobanian, A.V., Bakris, G.L., Black, H.R., et al. The Seventh Report of the Joint National Committee on Prevention, Detection, Evaluation, and Treatment of High Blood Pressure: the JNC 7 report. Jama, 2003. 289: 2560-72.

3. Whitworth, J.A. 2003 World Health Organization (WHO)/International Society of Hypertension (ISH) statement on management of hypertension. J Hypertens, 2003. 21: 1983-92.

4. National Collaborating Centre for Chronic Conditions., Hypertension: management of hypertension in adults in primary care: partial update. 2006, Royal College of Physicians,: London.

5. Collins, R., Peto, R., MacMahon, S., et al. Blood pressure, stroke, and coronary heart disease. Part 2, Short-term reductions in blood pressure: overview of randomised drug trials in their epidemiological context. Lancet, 1990. 335: 82738.

6. Dahlof, B., Sever, P.S., Poulter, N.R., et al. Prevention of cardiovascular events with an antihypertensive regimen of amlodipine adding perindopril as required versus atenolol adding bendroflumethiazide as required, in the AngloScandinavian Cardiac Outcomes Trial-Blood Pressure Lowering Arm (ASCOTBPLA): a multicentre randomised controlled trial. Lancet, 2005. 366: 895-906.

7. Centrum för Patientklassificering, Vårdkostnader och vårdtider 2002 för NordDRG (Treatment times and costs for NordDRG 2002, in Swedish). 2003, The National Board of Health and Welfare: Stockholm.

8. Netten, A.Curtis, L., Unit Costs of Health and Social Care 2002. 2003, Personal Social Services Research Unit, University of Kent.

9. Department of Health. NHS Reference Costs. 2005; Available from: http://www.doh.gov.uk/nhsexec/refcosts.htm\#spre Accessed.2005-12-05

10. FASS, Official Drug Price List. 2006, Stockholm: LINFO AB.

11. MIMS, Monthly Index of Medical Specialities. 2006: London.

12. Historical exchange rates. 2007; Available from: www.riksbanken.se Accessed.2007-03-28

13. Lindgren, P., Buxton, M., Kahan, T., et al. Cost-effectiveness of atorvastatin for the prevention of coronary and stroke events: an economic analysis of the AngloScandinavian Cardiac Outcomes Trial--lipid-lowering arm (ASCOT-LLA). Eur J Cardiovasc Prev Rehabil, 2005. 12: 29-36.

14. Sonnenberg, F.A.Beck, J.R. Markov models in medical decision making: a practical guide. Med Decis Making, 1993. 13: 322-38.

15. Human Mortality Database. 2006; Available from: www.mortality.org Accessed.2006-06-01

16. Läkemedelsförmånsnämnden, Läkemedelsförmånsnämnden allmänna råd om ekonomiska utvärderingar. 2003: Stockholm. 
17. National Institute of Clinical Excellence. Guide to the Methods of Technology Appraisal. 2004; Available from: http://www.nice.org.uk/page.aspx?o=201974 Accessed.2007-03-14

18. Lindgren, P., Kahan, T., Poulter, N., et al. Utility loss and indirect costs following cardiovascular events in hypertensive patients: the ASCOT health economic substudy. Eur J Health Econ, 2006.

19. Kind, P., Dolan, P., Gudex, C., et al. Variations in population health status: results from a United Kingdom national questionnaire survey. Bmj, 1998. 316: 736-41.

20. Burstrom, K., Johannesson, M.Diderichsen, F. Swedish population health-related quality of life results using the EQ-5D. Qual Life Res, 2001. 10: 621-35.

21. Lindgren, P., Stenestrand, U., Hambraeus, K., et al. PCI reduces utility loss after MI in Sweden. in World Congress of Cardiology. 2006.

22. Efron, B.Tibshirani, R., An introduction to the bootstrap. 1993, London: Chapman \& Hall/CRC.

23. Lothgren, M.Zethraeus, N. Definition, interpretation and calculation of costeffectiveness acceptability curves. Health Econ, 2000. 9: 623-30.

24. The Swedish National Board of Health and Welfare's Guidelines for Cardiac Care 2004 2004, The National Board of Health and Welfare: Stockholm.

25. Henriksson, F., Agardh, C.D., Berne, C., et al. Direct medical costs for patients with type 2 diabetes in Sweden. J Intern Med, 2000. 248: 387-96.

26. Johannesson, M., Meltzer, D.O'Conor, R.M. Incorporating future costs in medical cost-effectiveness analysis: Implications for the cost-effectiveness of the treatment of hypertension. Medical Decision Making, 1997. 17: 382-389.

27. Meltzer, D. Accounting for future costs in medical cost-effectiveness analysis. Journal of Health Economics, 1997. 16: 33-64.

28. Ekman, M., Two Essays in Health Economics. Consumption and Production by Age with Emphasis on Health Care Expenditures and Economic Evaluation of Beta-Blocker Therapy in Heart Failure, in Managerial Economics Section \& Centre for Health Economics. 2001, Stockholm School of Economics: Stockholm.

29. O'Brien, E. Protocol Summary and Sub-Study Protocols J Hum Hypertension, 2001. 15 Suppl 1: S3-11. 
Tables for online publication only

Table A1. Costs $(€)$ associated with the events in the model.

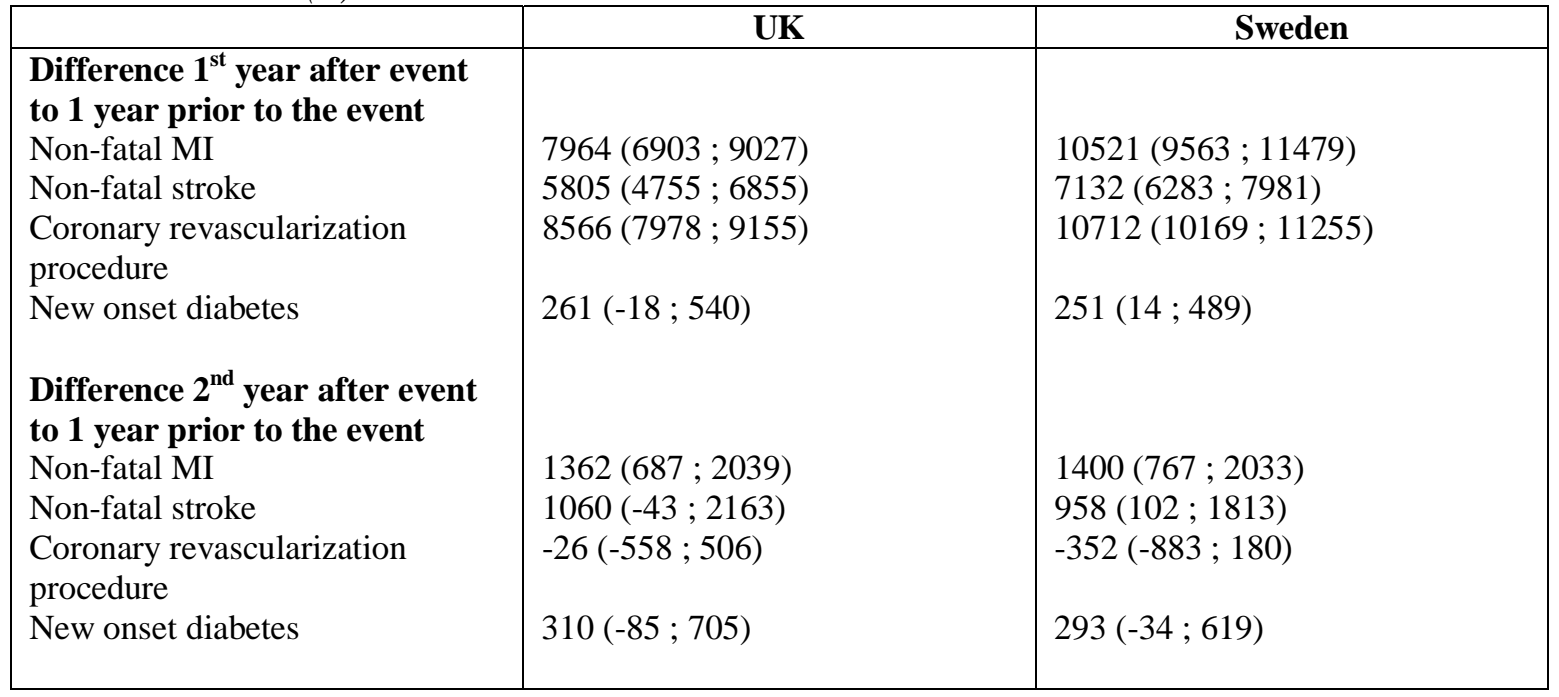

Mean values and 95\% confidence intrevals. $\mathrm{MI}=$ Myocardial infarction

Table A2. Sensitivity analysis.

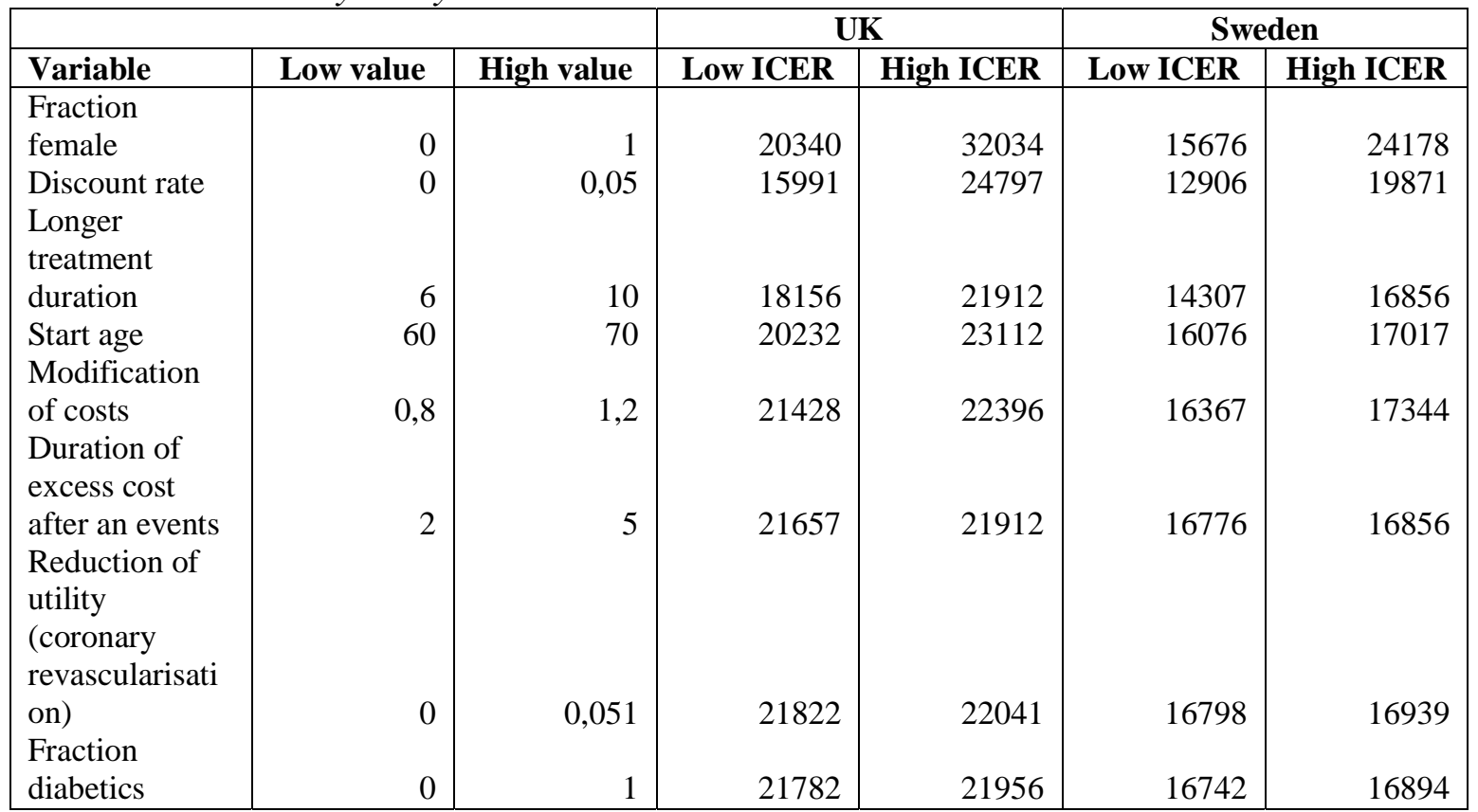

Costs in $€$. ICER = Incremental cost-effectiveness ratio 


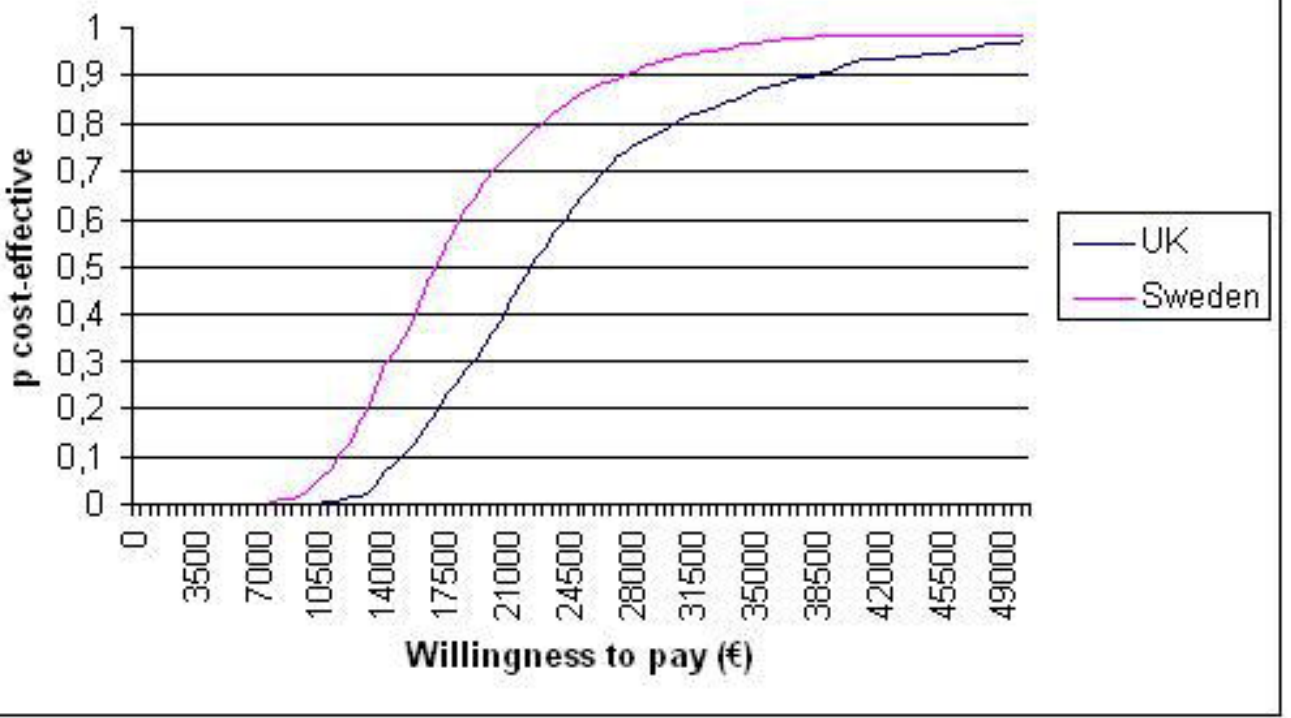

